English Education Journal

UNNES

http://journal.unnes.ac.id/sju/index.php/eej

\title{
The Realization of Hedges and Boosters in Trump's and Clinton's Utterances in The US Presidential Debates in 2016
}

\author{
Henny Kusumawati ${ }^{\bowtie}$, Dwi Rukmini, Januarius Mujiyanto \\ Universitas Negeri Semarang, Indonesia
}

\begin{tabular}{l}
\hline Article Info \\
\hline Article History: \\
Recived 12 November \\
2020 \\
Accepted 27 January \\
2021 \\
Published 20 June \\
2021 \\
\hline Keywords: \\
Boosters, Hedges, \\
Pragmatic Functions, \\
Political Discourse
\end{tabular}

\begin{abstract}
Hedges and boosters are crucial metadiscourse markers to soften and strengthen the proposition. Presidential candidates also rely on hedges and boosters to draw the publics' intentions. This study aims to explore the use of hedges and boosters in Trump's and Clinton's utterances in the US presidential debates in 2016. Accordingly, discourse analysis was adopted in this present study to find out the realization of types and functions of hedges and boosters as well as the differences and similarities of the occurrences of hedges and boosters between those two candidates based on the taxonomies of Salager-Meyer (1997), Demir (2017), Rabab'ah and Rumam (2015) and Hyland (2005). The strategy was elaborated into six sub-research questions to find out types, functions, differences, and similarities of hedges and boosters. The data were obtained from the transcript of the debates. The findings reveal that the seven types of hedges and six types of boosters were discovered in the utterances of Trump and Clinton. Associated with the functions of hedges and boosters, it shows that Trump and Clinton tend to use hedging devices to mitigate their claims by showing some kind of uncertainty. Boosters also applied to put emphasis on the value of the truth of their statements. It was discovered that Trump used more boosters and Clinton used more hedging devices as well.
\end{abstract}

$凶$ Correspondence Address:

Kampus Pascasarjana Universitas Negeri Semarang, J1 Kelud Utara 3,

p-ISSN 2087-0108

Semarang, 50233

e-ISSN 2502-4566

E-mail: hennykusumaa1@gmail.com 


\section{INTRODUCTION}

Politics is an effective way to reach goals. It is used to convince and make changes to people's attention (Janoschka, 2010) and subsequently their behavior. Especially in a presidential debate, a presidential debate is a public debate held during a general election campaign. The candidates expose their political opinions and public policy proposals, and criticism to potential voters (Kettle, 2010). Presidential candidates are supposed to verbalize their ideological stances, as well as socio-economic strategy plans in a way that looks persuasive to voters to defeat their political opponents and gain a significant number of votes. A whole rhetorical strategy spectrum from two subcategories of metadiscourse markers, hedges, and boosters may be applied by the candidates.

Hedging is one of the pragmatics competencies that correlated with it. Lakoff (1972) introduced the concept of hedges as a linguistic term. He described it as "words whose job it is to make things fuzzier or less fuzzy" (p. 195). In Lakoff's basic notion, hedges modify words or phrases within a proposition by formulating the sequence fuzzier or formulating the boundaryless vague. Hyland (1998a) also argued that hedges are linguistic strategies that are utilized to lessen categorical commitment; express possibility instead of certainty, for instance, "can, probably, possible," etc. Some linguists also define hedges as a number or uncertainty and limited word (Crystal, 1997), modification of proposition (Verschuren, 1999), and words of caution and annotative (Yule, 1996). Wilamova (2005) also argued the markers of pragmatics that used to weaken or soften an utterance. Thus hedges are applied to make the statement not to be rigid and very strong. Based on the definition above, hedges are strategies of linguistics that the interlocutor utilizes to evade sounding too straight or definite and overgeneralized.

On the other hand, boosters are utilized to convey the writer or interlocutor's certainty in what they express and to mark participation with the area of discussion and solidarity with the hearer (Hyland, 2005). Holmes (1982) and Meyer (1997) define the term 'boosters' as some lexical items to express a firm conviction of a statement. Peacock (2006) identified the functions of boosters as conveying several "accepted truth, evidential or implicit truth, and solidarity" (p.65). Thus, boosters are employed to demonstrate the interlocutor or writer's statements some amount of certainty.

Hedges and boosters are parts of communication skills, particularly in political discourse. Investigating the utilization of hedges and boosters in political discourse is beneficial since hedges and boosters are language devices that are frequently applied by the candidates to convey their messages to the public. By examining hedges and booster, scholars are in a position to reveal the linguistic masks of candidates. Therefore, they can divulge the "genuine" political messages candidates articulated to the public. Every alteration in that country would attract attention from other countries worldwide since the United States is a superpower country. Notably, it is a presidential election. The selected president would have an impact on some aspects, especially in economic and political elements globally, since a president has the right to make decisions and rules for the country. Those language devices are applied to deliver their messages to the people appropriately.

In some cases, they need to soften the utterance or even strengthen their statements. Therefore, by conducting the study, the researcher hopes to fill the gap by explaining the realization of hedges and boosters in Trump's and Clinton's utterances in the 
United States of America presidential debates in 2016. There is also some hidden meaning in hedges and boosters applied that is interesting to be explored.

\section{METHODS}

In this present study, the discourse analysis method was considered as the most appropriate research design to be adopted. It purposes to recognize how language is employed in real-life circumstances. This present research explored US Presidential debates when language was applied in a political setting. This study takes into account Trump's and Clinton's utterances during the first, second, and final debates in 2016. In this case, Trump was the representative of The Republic Party, and Clinton was the representative of The Democrat Party. The researcher explored the transcript of the debates to accomplish the objective of the study. In the first part of analyzing the data, the researcher investigated the types of hedges and booster and the classification of those pragmatics functions based on the taxonomy of Salager-Meyer (1997), Rabab'ah \& Rumman (2015), Hyland (2005), and Demir (2017) in Trump's and Clinton's utterances. Furthermore, quantifying the qualitative data was applied to explore the differences and the similarities of the occurrences of hedges and boosters.

\section{RESULTS AND DISCUSSIONS}

There are six themes of the data presented based on the research questions, types of hedges, types of boosters, functions of hedges, functions of boosters, the similarities, and the differences of hedges and boosters. The research results are presented the data to attain reliable discussion, including the tables and the examples of the data.

\section{Types of Hedges}

According to the result analysis, both US Presidential Candidates 2016, Trump and Clinton, applied hedging devices in their utterances. Some experts also describe political discourse as a nonscientific genre. Like any other humanistic or social discourse, political discourse uses hedging devices to express vagueness and lack of certainty. It means that Trump and Clinton soften their claims to reduce the strength of the commitment. The findings are in line with Taweel (2011); Jalilifar and Alavi (2011); Laurinaitytè (2011); Al- Rashady (2012); Rabab'ah and Rumman (2015); Idowu, Olubunmi, and Owuye (2019); Taweel (2011) that hedges play significant roles in political discourse. The types of hedges classified by Salager-Meyer (1997) are modal auxiliary verb, modal lexical verb, adjectival, adverbial and nominal modal phrase, approximator of degree, quantity, frequency, and time, introductory phrase, if clause, and compound hedges. Those types of hedges are found in the utterances of Trump and Clinton.

Firstly, the modal auxiliary verb is the most frequent type of hedges that occurred in Trump and Clinton's utterances in the debates, which are 304 modal auxiliary verbs. Furthermore, the findings are also in support of Laurinaityte (2011), Al- Rashady (2012), Rabab' ah, and Rumman (2015) that modal auxiliary verb was the most commonly applied in his research. The analysis result revealed that the modal auxiliary verb "would" was the most dominant one. On the contrary, modal auxiliary "can" is the most frequent hedge discovered in their findings. In line with Laurinaityte (2011), a modal auxiliary verb is applied to convey probability or possibility triumphed rather than express speculation or predictions. The example depicts below :

(1) I would be a president for all of the people, African-Americans, the inner cities. (T2) 
In excerpt 1, the modal auxiliary "would" is found in Trump's utterance in the second debate. By using the modal auxiliary verb "would," Trump tried to predict that he was the elected president in 2016. However, he softened his statement if he was selected to be a president. He was not sure about becoming president for all people, African- Americans, and the inner cities. Clinton said in the debate that Trump was a racist. Thus, the hedge "would" is applied

The second type of booster that dominated in Trump and Clinton's utterances is approximators of degree, quantity, frequency, and time. The analysis revealed 255 approximators of degree, quantity, frequency, and time in the debates. This type of hedges is applied to make the statement vague since the speakers cannot express the figure precisely. The findings are in proportion to Salager-Meyer (1997), Vartalla (2001), and Vebriyanto (2019) that the speakers do not have adequate knowledge to state the exact figure. In this case, the highest proportion is "some." It is illustrated that the speaker did not display the exact degree of quantity in the statement. The example depicts below:

(2) They're building some of the biggest plants anywhere in the world, some of the most sophisticated, some of the best plants. (T1)

In excerpt 2, an approximator of quantity "some" was discovered in Trump's utterance in the first debate. The use of approximator of quantity "some" is to express the indefiniteness meaning of the number of the plans. In this case, the audiences cannot exactly judge what kind of plants he referred to when Trump began talking about America's downturn economic situation. Thus the hedge "some" was applied.

The third type of hedges applied by Trump and Clinton in the US presidential debates in 2016 is the introductory phrase. The frequency of this type appeared in the debates is 244 times. The hedging device that widely occurred is "Ithink." The use of the introductory phrase is to express their personal opinion and also direct involvement. Since it is a personal point of view, it can prevent them from other criticism. This finding confirms the study conducted by Laurinaityte (2011) and Rabab'ah and Rumam (2015). The example depicts below:

(3) I think what the FBI did and what the Department of Justice did, including meeting with her husband, the attorney general, in the back of an airplane on the tarmac in Arizona (T3)

In excerpt 3 , the introductory phrase "I think" was discovered in Trump's utterance in the third debate. The use of the introductory phrase "I think" shows that Trump stated his personal opinion about what the FBI and the Department of Justice had done that is disgraceful. Thus the hedges "I think" were employed.

The fourth type of hedging device discussed in this part is the if clause. "If clause" is an attribute in political discourse. According to the analysis result, this type of hedges occurred 97 times in Trump's and Clinton's utterances in the debates. "If clause" hedge is used to express doubt and uncertainty of the proposition. It is in line with the study conducted by Laurinaityte (2011, p.70) that conditionals or if clause employed by the politicians "due to their hypothetical nature that allows speculating." In the analysis, the result shows that Trump and Clinton mostly applied conditionals to predict future consequences. It confirms the study conducted by Rabab'ah and Rumam (2015). The example depicts below:

(4) If we set those goals and we go together to try to achieve them, there's nothing, in my opinion, that America can't do. (C2)

In excerpt 4, the "if clause" hedge was discovered in Clinton's utterance in the second debate. The use of the "if clause" shows that Clinton was uncertain about her future possibility that would 
positively impact America's economy, education, and any other aspects. However, this could be achieved or not in the future. Thus the hedge "if clause:" was applied.

The fifth type of hedges that dominated Trump's and Clinton's utterances is adjectival, adverbial, and nominal modal phrases. Based on the finding, it shows that this type of hedges applied 92 times in the debates. The word that mostly appeared is "maybe," an adverbial modal phrase. This type of hedge is employed to express some kind of uncertainty of claim. According to Navrátilová (2013), an adverbial booster is applied to evaluate the certainty, uncertainty, truth, or falsity of statements. It also in line with the study conducted by Rabab'ah and Rumam (2015) that the degree of probability and uncertainty is expressed using the adverbial modal phrase. The example depicts below:

The sixth type of hedges applied by Trump and Clinton in the US Presidential debates in 2016 is the modal lexical verb. This type of hedges is used to express the speakers' personal opinion, as proposed by Salager-Meyer (1997). The findings revealed that the modal lexical verb appeared 78 times. The highest modal lexical verb is "believe." In this case, the speakers applied a modal lexical verb "believe" to show their point of view toward their proposition so that it can avoid direct criticism from others. Here are the examples of modal lexical verbs :

(1) We haven't even started. And we've spent \$6 trillion in the Middle East, according to a report that I just saw. Whether it's 6 or 5, but it looks like it's 6, \$6 trillion in the Middle East, we could have rebuilt our country twice. (T1)

In excerpt 1, the modal lexical verb "looks like" was found in Trump's utterance in the first debate. The use of a modal lexical verb "looks like" shows that Trump was not sure about the amount of money spent on the Middle East. He seems doubtful whether it was $\$ 5$ or $\$ 6$ trillion. Thus the hedge "looks like" was applied

The seventh type of hedges used by Trump and Clinton in the US Presidential debates in 2016 is compound hedges. Compound hedges are the least favored types of hedges laid by Trump and Clinton. This finding is in keeping with the study done by AlRashady (2012). The hedge that occurred is "I kind of assume." In this case, the compound hedge is used to express some kind of uncertainty and doubt.

\section{Types of Boosters}

Instead of softening their claims, boosters are also applied by Trump and Clinton to intensify their propositions. According to the result analysis in the previous part, all types of boosters occurred in the utterances of Trump and Clinton. Boosters applied by Trump and Clinton are mostly to strengthen their commitments or claims. This present research applied types of booster adapted from Demir (2017), namely modal booster, verbal booster, adjectival booster, adverbial booster, quantifiers/determiner, and noun booster.

The first type of booster that widely occurred in Trump's and Clinton's utterances in the debates is the adjectival booster. It appeared 642 times in the debates. Findings proved a high tendency of using the adjectival booster. The most frequent booster that appeared is "great." According to the analysis result, Trump and Clinton applied adjectival boosters to pledge their proposition or even persuade other people. This finding is in line with the study conducted by Vassileva (2001) and Demir (2017) that adjectival and adverbial boosters are English and Bulgarian classrooms. This study also confirms the result investigated by Ilham et al. (2019) that adjectival and verbal booster are used by speakers to express their assertions to the audiences. 
The second type of booster that was prominently found in the utterances of Trump and Clinton in the debates is the adverbial booster. It occurred 555 times in Trump's and Clinton's statements. The most frequent booster that appeared is "very." This finding is in line with Vassileva (2001), Kennedy (2003), Demir (2017), and Friginal, Lee, Polat, and Roberson (2017) that "very" is also prominently used in speeches. Based on the examples explained before, this booster is applied to intensify the meaning of the speakers' claims.

(1) That means jobs in infrastructure, in advanced manufacturing, innovation and technology, clean, renewable energy, and small business because most of the new jobs will come from small businesses.

Then, in excerpt 2, the modal booster "will" was discovered in Clinton's utterance in the first debate. Clinton tried to emphasize that her plans would positively impact the economic situation, especially in small businesses, by using modal booster "will." Since, according to her, the economy only worked for people at the top. Thus, she had a great intention to accomplish her future plan if she would be a president.

Modal booster is another type of booster that is also highly employed by both candidates in the debates. This type of booster occurred 368 times in the utterances of Trump and Clinton. The analysis result revealed that the modal booster, "will" is the most dominant one. This finding is in line with Peacock (2006) and Hyland (199b) that modal auxiliary "will" is the most dominant booster. Trump and Clinton use it to express their strong convictions to the hearer. As proposed by Demir (2017), a modal booster is a strong booster.

The fourth type of booster that mostly appeared in the debates is quantifier/determiner. This type of booster is dominated by the word "all." This result is in concert with Salichah (2015) and
Vebriyanto et al. (2019). Based on the analysis result, it is used to exaggerate the meaning of the speakers' proposition.

The fifth type of booster mostly applied by Trump and Clinton is a verbal booster. Verbal booster appeared 342 times in Trump and Clinton's utterances in the first, second, and final debate. This type of booster is realized linguistically by verbal booster "make sure." This finding is different from Peacock (2006) and Vebriyanto et al. (2019) that the verb "show" is the most dominant one. In this case, a verbal booster is used "to persuade the reader to the truthiness of their claims, or the importance and necessity" and show shreds of evidence provided, Demir (2017, p.601).

The least favored type of booster applied by Trump and Clinton is a noun booster. This type of booster appeared 329 times in the utterances of Trump and Clinton. The analysis result revealed that noun booster mostly performed the word "deal." In this case, a noun booster has the function of emphasizing the truth value of the statement.

\section{Functions of Hedges}

This part provides the discussion about the realization of functions of hedges in the utterances of Trump and Clinton in the debates. The pragmatics function of hedges applied in this present research was adapted from Rabab'an and Rumam (2015). Those are mitigating claims by showing some kind of uncertainty, expressing lack of full commitment, expressing politeness and searching for acceptance, avoiding direct criticism, mainly when predicting future events or consequences, and requesting the listeners' involvement.

The first pragmatic function of hedge that was highly applied by Trump and Clinton in the US Presidential debates in 2016 is mitigating claims by showing some kind of uncertainty. Mitigating claims 
by showing some kind of uncertainty occurred 470 times in some types of hedges uttered by Trump and Clinton. This result is in line with Martin-Martin (2009), Navrátilová (2013), Saputra (2013), and Simpson (2010). As the analysis result shows, this function is performed by some types of hedges: modal auxiliary verb and approximators of degree, quantity, frequency, and time in line with Al-Rashadi (2012). This function is applied to add a sense of uncertainty, and the strength of claims is reduced. This finding is contradicted the study conducted by Rabab'ah and Rumam (2015), protecting from being criticized is the most prominent function used. It can be seen from the examples that Trump and Clinton try to show some fuzziness and lack of precision in their claims. Here is the following excerpt:

(1) Last year, we had an almost $\$ 800$ billion trade deficit; it's hard to believe. (T2)

In excerpt 1 , the approximator of quantity "almost" was found in Trump's utterance in the second debate. When Trump talked about the previous government's decisions, who was Obama, he stated that the previous government did use the tremendous potential in business and trade. As a result, the country had a trade deficit. In expressing the amount of trade deficit, Trump applied the hedge "almost" to show its uncertainty. It shows that he was lack of knowledge to state the exact amount of the trade deficit (Rab'ah \&Rumam, 2015).

Expressing politeness and searching for being accepted is the second prominent pragmatic function that appeared in Trump and Clinton's utterances. This function was applied 310 times in the debates. It is realized linguistically mostly by "introductory phrase." It shows that "I think" dominantly occurred in the analysis. The analysis result is in line with the study conducted by Mentari (2010). This function is applied to express politeness. It confirms the research of Taweel et al. (2011, p.26) that "politeness is as much the conveyer of hedging, as the hedging is the conveyer of politeness. This concluding statement stems from the fact that all hedging devices, to a greater or lesser degree, do convey politeness". It shows in the examples that both candidates applied the function to be accepted by the audiences since their arguments might contradict the audiences' interest.

The third function of the hedge that dominates the occurrences of hedging devices is avoiding direct criticism significantly when predicting future events or consequences. It appeared 203 times in the utterances of Trump and Clinton in the US Presidential debates in 2016. According to the analysis result, the most frequent type of hedges that occurred is "modal auxiliary verb" in line with Hyland (1996). As shown in the examples, this function is used to express messages politely to the audiences and avoid others' criticism. It is in line with the study conducted by Rabab'ah and Rumam (2015).

Another function of hedges found in the utterances of Trump and Clinton is requesting the listeners' involvement. It was uttered 85 by both of the candidates in the debates. The introductory phrase type of hedges mostly performs this function. The findings confirm the study conducted by Laurinaityte (2011) and Rabab'ah and Rumam (2015). It is shown in the examples employed by Trump and Clinton that this type of function is used to express the direct involvement of the audiences in the debates.

The fifth function applied by Trump and Clinton in the debates is expressing a lack of full commitment. According to the analysis result, expressing a lack of full commitment is the least favored one. It occurred 67 times in the utterances of Trump and Clinton. This function is dominated by the type of hedges of a modal auxiliary verb. It is realized linguistically mostly by "can." The finding is in line with the study conducted by Rabab'an and 
Rumam (2015) that the speakers avoid being fully committed.

\section{Functions of Boosters}

In this part, the researcher discusses the realization of the pragmatic functions of types of boosters. The pragmatic functions adapted from Hyland (2005) were applied to find out the realization of the functions of types of boosters in Trump's and Clinton's utterances. He divided the functions of boosters into two categories. Those categories are emphatic and amplifier.

Based on the analysis result, the most dominant pragmatic function in Trump and Clinton's utterances in the debates is emphatic. Emphatic occurred 1375 times in both of the candidates. It is realized linguistically mostly by modal booster, which is "will." As shown in the examples in the previous part, this function is applied to emphasize the truth value of the statements. This finding is in line with Al-Ghoweri and Al Kayed (2019). The study conducted in English and Jordanian economic newspaper articles also found that emphatic is the most frequent appeared.

Another pragmatic function applied by Trump and Clinton in the debates is amplifiers. Based on the analysis result, it occurred 1223 times in the debates. It is realized linguistically mostly by "very." It is used to intensify the meaning of the utterances. This finding is in line with the study conducted by Alshaar (2017), Kennedy (2003), and Friginal, Lee, Polat, and Roberson (2017). Here is the following excerpt:

(2) Well, what Russia did with Assad and, by the way, with Iran, whom you made very powerful with the dumbest deal perhaps I've ever seen in the history of dealmaking, the Iran deal, with the $\$ 150$ billion, with the $\$ 1.7$ billion in cash, which is enough to fill up this room. (T2)

In excerpt 2, an adverbial booster "very" was found in Trump's utterance in the second debate. The use of an adverbial booster "very" shows that Trump exaggerates how powerful Iran after the deal was made. Thus it functioned as an amplifier.

\section{The Differences}

This part presents the differences in the use of hedges and boosters in Trump and Clinton's utterances in the debates. It discusses the occurrences of hedges and booster based on the findings. Firstly, Clinton applied more hedging devices than Trump in the debates. Even though in the first debate, Trump used more hedging devices, which are 237 and 233 in Clinton's utterances. Secondly, Clinton applied all types of hedges in the three debates; however, not all types of hedges are used by Trump in his statements, such as adjectival modal phrase and nominal modal phrase. Thirdly, Trump employed more boosters rather than Clinton. It is shown in the first debate that there are 508 booster items uttered by Trump and 319 booster items uttered by Clinton

\section{The Similarities}

This part discusses the similarities of the realization of hedges and boosters in the utterances of Trump and Clinton in the US Presidential Debates in 2016. In this case, the researcher compared the occurrences of hedges, and boosters realized in the statements. The most frequent function of hedges in Trump and Clinton's statements during the debates is mitigating claims by showing some kinds of uncertainty. The total is 209 times in Trump's utterances and 214 times in Clinton's statements. Both Trump and Clinton have used all types of boosters such as modal booster, verbal booster, adjectival booster, adverbial booster, quantifier/determiner, and noun booster. The finding also appeared to prove that the function of boosters, emphatic, is used more frequently than the amplifier function. 


\section{CONCLUSIONS}

This part presents five conclusions based on the research questions mentioned previously. The first conclusion is dealing with the realization of types of booster used by Trump and Clinton's utterances in the debates. A modal auxiliary verb is the type of hedges that the most frequently occurred in Trump and Clinton's statements in the debates, and compound hedges are the least favored ones. The second conclusion is dealing with the types of boosters realized in Trump and Clinton's utterances in the debates. Based on the findings, it can be concluded that Trump and Clinton applied all types of boosters: a modal booster, verbal booster, adjectival booster, adverbial booster, quantifier/determiner, and noun booster. The type of booster that frequently occurred is an adjectival booster.

Furthermore, the lowest type of booster identified in Trump and Clinton's utterances is a noun booster. The third conclusion drawn from the findings is dealing with the realization of the function of hedges in Trump's and Clinton's utterances. The most dominant function applied by Trump and Clinton is mitigating claims by showing some kind of uncertainty. This function is applied to add a sense of uncertainty, and the strength of assertions is reduced. Furthermore, the function of hedges that both candidates rarely use is expressing a lack of full commitment.

The fourth conclusion in this present research is the realization of the functions of boosters. The findings appear to prove that emphatic is the most frequent function applied by Trump and Clinton in the utterances. This function is used to express to emphasize the force or speakers' certainty in messages.
The fifth conclusion is dealing with the differences in the use of hedges and boosters in Trump and Clinton's utterances in the debates. Firstly, hedging devices are applied more by Clinton rather than Trump. Secondly, Clinton applied all types of hedges in the three debates. However, not all types of hedges are used by Trump in his utterances, such as adjectival modal phrase and nominal modal phrase. Thirdly, Trump employed more boosters rather than Clinton.

This part discusses the similarities of the realization of hedges and boosters in Trump and Clinton's utterances in the US Presidential Debates in 2016. The most frequent function of hedges in Trump and Clinton's statements during the debates is mitigating claims by showing some kind of uncertainty. Both Trump and Clinton have used all types of boosters such as modal booster, verbal booster, adjectival booster, adverbial booster, quantifier/determiner, and noun booster. Lastly, both candidates used more emphatic function in their booster expression than amplifiers in their utterances.

\section{REFERENCES}

Al-Ghoweri, H. A., \& Al Kayed, M. M. (2019). A comparative study of hedges and boosters in English and Jordanian Arabic: economic newspaper articles as a case study. Theory and Practice in Language Studies, 9(1), 52-59.

Demir, C. (2017). Competence in lexical boosters and nativeness in academic writing of English: The possible relation. Journal of Language and Linguistic Studies, 13(2), 593-614.

Friginal, E., Lee, J. J., Polat, B., \& Roberson, A. (2017). Exploring spoken English learner language using corpora: Learner talk. Springer.

Hedges, L. G. (1972). A study in meaning criteria and the logic of fuzzy concepts. Chicago Linguistic Society Papers, 8, 183-228.

Holmes, J. (1990). Hedges and boosters in women's and men's speech. Language \& Communication, 10(3), 185-205. 
Hyland, K. (1996). 'I don't quite follow': Making sense of a modifier. Language Awareness, 5(2), 91-109.

Hyland, K. (1996). Talking to the academy: Forms of hedging in science research articles. Written Communication, 13(2), 251-281.

Hyland, K. (2005). Stance and engagement: A model of interaction in academic discourse. Discourse Studies, 7(2), 173-192.

Ilham, I., Nababan, M. R., Kristina, D., \& Wiratno, T. (2019, August). The analysis of booster expression in the complaining speech act. In Fifth Prasasti International Seminar on Linguistics (PRASASTI 2019). Atlantis Press.

Jalilifar, A. R., \& Alavi, M. (2011). Power and politics of language use: a survey of hedging devices in political interviews. The Journal of Teaching Language Skills (JTLS) Previously Journal of Social Sciences \& Humanities, 34(64).

Janoschka, A. (2010). Direct e-communication: Linguistic weapons in a political weblog.). Perspectives in Politics and Discourse 36, 215-236.

Kennedy, G. (2003). Amplifier collocations in the British national corpus: Implications for English language teaching. TESOL Quarterly, 37(3), 467- 487.

Kettle, M. (2010). All eyes on the leaders' debates. The Guardian.

Laurinaitytè, R., Selmistraitis, L., \& Kozačǐ̌če, J. (2011). Hedges in political discourse. 133.

Owuye, M. O., \& Idowu, O. A. (2019). Linguistic modality in Ghanaian President Nana Addo Dankwa Akufo-Addo's 2017 inaugural address. European Journal of Social Sciences, 58(2), 134-142.

Peacock, M. (2006). A cross-disciplinary comparison of boosting in research articles. Corpora, 1(1), 61-84. http://doi:10.3366/cor.2006.1.1.61

Raba'ah, G., \& Abu Rumman, R. (2015). Hedging in political discourse: evidence from the speeches of King Abdullah II of Jordan. Prague Journal of English Studies, 4(1), 157-185.

Rashady, F. A. (2012). Determining the role of hedging devices in the political discourse of two American presidents in 2008. TESOL Journal, 7, 30-42.

Salager-Meyer, F. (1997). I think that perhaps you should: A study of hedges in written scientific discourse. Functional approaches to written text: Classroom applications, 105-118.

Salichah, I., Irawati, E., \& Basthomi, Y. (2015). Hedges and boosters in undergraduate students' research articles. Jurnal Pendidikan Hummaniora, 3(2), 154-160.

Taweel, A. Q., Saidat, E. M., Rafayah, H. A., \& Saidat, A. M. (2011). Hedging in political discourse. The Linguistics Journal, 5(1), 169196.

Vassileva, I. (2001). Commitment and detachment in English and Bulgarian academic writing. English for specific purposes, 20(1), 83-102.

Vebriyanto, D. A., \& Mujiyanto, J. (2019). Types and functions of hedges and boosters in graduate students' research articles. English Education Journal, 9(4), 565-574.

Yule, G. (1996). Pragmatics. Oxford: Oxford University Press. 